\title{
Absorption of strawberry phytochemicals and antioxidant status changes in humans
}

\author{
E. Azzini ${ }^{\mathrm{a}, *}$, F. Intorre ${ }^{\mathrm{a}}$, P. Vitaglione ${ }^{\mathrm{b}}$, A. Napolitano ${ }^{\mathrm{b}}$, M.S. Foddai ${ }^{\mathrm{a}}$, A. Durazzo ${ }^{\mathrm{a}}$, \\ A. Fumagallia , G. Catasta ${ }^{a}$, L. Rossi ${ }^{\mathrm{a}}$, E. Venneria ${ }^{\mathrm{a}}$, M.F. Testa ${ }^{\mathrm{a}}$, A. Raguzzini ${ }^{\mathrm{a}}$, L. Palomba ${ }^{\mathrm{a}}$, \\ V. Fogliano ${ }^{\mathrm{b}}$ and G. Maiani ${ }^{\mathrm{a}}$ \\ ${ }^{\mathrm{a}}$ National Institute for Food and Nutrition Research, Rome, Italy \\ b Department of Food Science, University of Napoli "Federico II", Naples, Italy
}

\begin{abstract}
In this study the antioxidant composition of fresh and stored strawberries and the bioavailability of the main strawberry bioactive compounds were determined in humans. In addition we have investigated plasma total antioxidant capacity. On 13 healthy volunteers, blood samples were collected before and after acute ingestion of fresh and stored strawberries, $300 \mathrm{~g}$ respectively. Ferric Reducing Antioxidant Power (FRAP) values after consumption of fresh and stored strawberries showed a significant increase $(P<0.05)$ at 5 and 8 hours time interval, while significantly decreased TRAP (Total Radical-Trapping Antioxidant Parameter) values $(P<0.05)$ were found at 8 hours respect to baseline after stored strawberries consumption. After consuming fresh strawberries, plasma levels of $\alpha$-carotene increased significantly $(P<0.05)$ respect to stored ones. Moreover, consumption of fresh and stored strawberries resulted in a significant increase of vitamin $\mathrm{C}$ at 2,3 and 5 hours $(P<0.05)$. The bioavailable amount of strawberries antioxidant compounds reflects the variations observed in fresh and stored fruits. We could summarize that the global food quality is related to both native quantity of bioactive compounds and storage treatments.
\end{abstract}

Keywords: Strawberry, domestic storage, bioactive compounds, plasma antioxidant status

\section{Introduction}

Recently the researchers have focused their attention on the beneficial effects of berry fruits (blueberries, blackberries, strawberries, raspberries) $[5,7,19,23,25,31]$, due to their composition in bioactive molecules such as anthocyanins, flavanols and catechins [13, 15, 16, 21, 22, 27, 29, 33, 38, 42, 45]. Studies conducted in vitro and ex vivo using strawberries, as well as other plant food, indicate that phytochemicals exert a wide range of biochemical actions including antioxidant, immunomodulating, inhibition of platelet aggregation and anticarcinogenic action $[2,30,32,41,43]$. Several studies have shown that the antioxidant capacity of strawberries extracts was positively related to their antiproliferative activities [52]. Some constituents of strawberries have shown inhibition of initiation and promotion of the carcinogenic process [20]. Zunino et al. [56] have investigated the ability of purified strawberry fractions to induce apoptotic cell death in leukaemia cells. Zhang et al. [55] have identified strawberry phenolics with antioxidant and human cancer cell antiproliferative activities.

Studies focusing on anthocyanins absorption have shown that the bioavailability of anthocyanins is quite low and their metabolism is still not fully understood $[7,9,37,53]$.

Human studies evaluating the biological properties and bioavailability of strawberry phytochemicals and impact of strawberries consumption on human health are needed.

${ }^{*}$ Corresponding author. E-mail: azzini@inran.it. 
Strawberries (Fragaria $\times$ ananassa Duch.) are a rich source of micronutrients and phytochemicals such as $\alpha$-carotene, vitamin $\mathrm{C}$ and phenolic compounds $[14,49,50]$ including ellagic-acid-containing compounds, proanthocyanidins, quercetin, kampferol and anthocyanins, mainly pelargonidin glycosides [8, 54]. The high antioxidant capacities associated with the relative content of bioactive nutrients was influenced by several factors including storage [19], as known, during storage several degradation reactions may occur reducing quality of strawberry [3, 39, $47,48]$.

The data reported in this work originate from a wider study in which bioavailability of strawberries antioxidants on humans was investigated [4].

Thus, the aim of present work was to examine the effect of domestic storage on the micronutrient and phytochemical composition of strawberries and to investigate the effects of acute strawberries consumption in humans on total antioxidant capacity and plasma antioxidant levels.

\section{Materials and methods}

\subsection{Chemicals}

All solvent were purchased from Carlo Erba (Milan, Italy), BDH (Poole, England) and Merck (Darmstadt, Germany). 2,2'-Azobis (2-amidinopropane) dihydrochloride (ABAP) was purchased from Wako Chemical (Germany), 2,4,6-tri(2-pyridyl)-s-triazine (TPTZ) was from Fluka (Switzerland). R-phycoerythrin (R-PE), phosphate-buffered saline (PBS), 6-hydroxy-2,5,7,8-tetramethylchroman-2-carboxylic acid (Trolox) and ascorbic acid were provided by Sigma-Aldrich Srl. Commercial standards were also from Sigma-Aldrich Srl (Milan, Italy). Double distilled water (Millipore, Milan, Italy) was used throughout the study.

\subsection{Subjects}

Thirteen volunteers ( 9 males and 4 females) were screened and enrolled in the study according to absence of acute or chronic diseases or metabolic disorders, no smoking habits, no alcohol consumption, no use of drugs, vitamin or mineral supplements for 2 weeks before the investigation. Mean age and BMI of the subjects were $26 \pm 7$ years and $22.6 \pm 2.6 \mathrm{~kg} / \mathrm{m}^{2}$.

\subsection{Strawberries}

Strawberries (cv Favetta) were grown in southern Lazio (Latina, Italy) by local producers. Fresh or stored strawberries derived from the same genotype and pre-harvest period.

Once received, they were immediately washed and divided into two parts. One half was used as fresh product (fresh strawberries), while the other part was stored at $+4^{\circ} \mathrm{C}$ over a 4 -day period and then used as stored strawberries. On the experimental days participants were served with $300 \mathrm{~g}$ portions of fresh or stored strawberries. The amount of bioactive compounds ingested by subjects was evaluated using the methods described below.

\subsection{Study design}

The recruitment of volunteers took place in different centres (Universities, Research Institutes), the study protocol was approved by the University of Rome "La Sapienza" Ethical Committee and all participants gave their written consent.

Three days before the study volunteers followed a low antioxidants diet, excluding some fruits, vegetables and beverages (wash-out). After fasting overnight, venous blood samples were collected (baseline). Following acute ingestion of fresh strawberries ( $300 \mathrm{~g}$ ), blood samples were collected at $0.5,1,2,3,5,8$ hours.

The same procedure was adopted after 4 days administrating $300 \mathrm{~g}$ of stored strawberries $\left(\right.$ at $+4^{\circ} \mathrm{C}$ ). 


\subsection{Samples treatment}

Blood samples were collected in EDTA containing tubes. After centrifuging at $3000 \mathrm{rpm}$ for $10 \mathrm{~min}$ at $4^{\circ} \mathrm{C}$ the plasma was stored at $-80^{\circ} \mathrm{C}$ until analysis. Aliquots of plasma were used for the following determinations: total antioxidant capacity, lipidemic profile, uric acid, vitamin $\mathrm{A}$ and $\mathrm{E}$, vitamin $\mathrm{C}$, carotenoids.

\subsection{Food analyses}

\subsubsection{Total antioxidant capacity}

The Total Antioxidant Capacity was evaluated by the Ferric Reducing Antioxidant Power (FRAP) [6] and Total Radical-Trapping Antioxidant Parameter (TRAP) [17] method. FRAP assay measures the reducing power-the ability of plasma samples to reduce the colorless ferric-tripyridyltriazine complex $\left(\mathrm{TPTZ}^{\mathrm{F}} \mathrm{Fe}^{3+}\right)$ to its ferrous colored form $\left(\mathrm{TPTZ}-\mathrm{Fe}^{2+}\right)$. It is a simple and highly reproducible spectrophotometric assay using Fe(II) as standard. The TRAP was determined according to the method of Ghiselli et al. [17] that was based on the protection provided by antioxidants on the fluorescence decay of $R$-phycoerythrin (lag phase) during a controlled peroxidation reaction.

\subsubsection{Carotenoids}

Carotenoids were extracted using the method described by Sharpless et al. [46]. The determination of carotenoid concentrations was carried out by high performance liquid chromatography techniques (HPLC) [34].

\subsubsection{Phenolics and total ascorbic acid}

Phenolics and total ascorbic acid were extracted from strawberries using the methods previously described by Hertog et al [22] and Margolis et al. [35] respectively. The quantitative analyses were performed using an HPLC system equipped with a coulometric detector (ESA model 580, Chemsford, MA, USA). The chromatographic separation was obtained applying the methods described by Serafini et al. [44].

\subsubsection{Anthocyanins}

Anthocyanins were extracted by a method adapted from Kay et al. [26]. The extracts were analysed by highperformance liquid chromatography with mass spectrometry (HPLC-MS) detection, using the analytical conditions previously described by Vitaglione et al. [51].

\subsection{Biological samples assessment}

Plasma total antioxidant capacity was measured by both FRAP [6] and TRAP method [17]. Total cholesterol and triglycerides were evaluated using commercial kits. Plasma uric acid was measured by spectrophotometric assay with a commercial kit. The spectrophotometric assay for measuring thiol groups was based on DTNB or Ellman reagent which reacts with $\mathrm{SH}$ groups leading to the formation of a colored solution which shows a maximum absorption at $412 \mathrm{~nm}[24]$.

The quantitative analysis of plasma carotenoids (lutein and zeaxanthin, cryptoxanthin, lycopene, $\alpha$-carotene, $\beta$-carotene), vitamin A and vitamin E was carried out by HPLC [34]. Total vitamin C was extracted from plasma and quantified according to Margolis et al. $[35,36]$. The quantitative analysis was done by HPLC like strawberries analysis.

\subsection{Statistical analysis}

All data were checked for normal distribution using Shapiro-Wilk's test. $t$-Test for dependent samples was applied for statistical analysis of food and dietary intake. For biological samples statistical analysis was performed using ANOVA test for repeated measures and the Bonferroni's 2-tailed $t$-test matched pairs test assuming the baseline values as reference category. $P<0.05$ was considered significant. 


\section{Results and discussion}

Strawberry breeding programs are currently used to improve specific agronomic, qualitative and sensorial characteristics and to increase strawberry fruit nutritional quality [11]. To identify a suitable cultivar for the study, different agricultural ecotypes of strawberries were analyzed: strawberry "Aprica" (Lombardia, North Italy), strawberry "Favetta di Terracina" (Lazio, Centre Italy), strawberry "Mara des Bois" (Calabria, South Italy), commercial strawberry (imported from Spain and available on market place).

For each selected product was evaluated the content of the most representative bioactive compounds in strawberries such as polyphenols, carotenoids and vitamin C. TRAP and FRAP were also evaluated as measure of antioxidant capacity.

In Table 1, "Favetta di Terracina" showed a total antioxidant capacity (FRAP $18.80 \pm 0.70 \mathrm{mmol} / \mathrm{kg}$ and TRAP $10.02 \pm 0.68 \mathrm{mmol} / \mathrm{kg})$ and single antioxidants content $(7.10 \pm 1.70 \mathrm{mg} / 100 \mathrm{~g}, 5.0 \pm 0.30 \mathrm{mg} / 100 \mathrm{~g}$, $1.16 \pm 0.40 \mathrm{mg} / 100 \mathrm{~g}$ and $55.7 \pm 2.5 \mathrm{mg} / 100 \mathrm{~g}$ for coumaric acid, quercetin, kampferol and vitamin $\mathrm{C}$ respectively) higher than "Mara des Bois" (FRAP $17.78 \pm 0.43 \mathrm{mmol} / \mathrm{kg}, \quad$ TRAP $9.87 \pm 0.28 \mathrm{mmol} / \mathrm{kg}$, coumaric acid $1.24 \pm 0.20 \mathrm{mg} / 100 \mathrm{~g}$, quercetin $3.10 \pm 0.04 \mathrm{mg} / 100 \mathrm{~g}$, kampferol $1.56 \pm 0.59 \mathrm{mg} / 100 \mathrm{~g}$, vitamin C $49.8 \pm 3.5 \mathrm{mg} / 100 \mathrm{~g}$ ) and commercial strawberries (FRAP $19.74 \pm 0.68 \mathrm{mmol} / \mathrm{kg}$, TRAP $10.34 \pm 0.15 \mathrm{mmol} / \mathrm{kg}$, coumaric acid $1.87 \pm 0.84 \mathrm{mg} / 100 \mathrm{~g}$, quercetin $2.06 \pm 0.87 \mathrm{mg} / 100 \mathrm{~g}$, kampferol $1.14 \pm 0.01 \mathrm{mg} / 100 \mathrm{~g}$, vitamin C $44.2 \pm 2.8 \mathrm{mg} / 100 \mathrm{~g}$ ). Although "Aprica" showed the highest values as wild ecotype (FRAP $62.85 \pm 3.23 \mathrm{mmol} / \mathrm{kg}$, TRAP $16.31 \pm 1.20 \mathrm{mmol} / \mathrm{kg}$, coumaric acid $0.80 \pm 0.31 \mathrm{mg} / 100 \mathrm{~g}$, quercetin $2.46 \pm 0.45 \mathrm{mg} / 100 \mathrm{~g}$, kampferol $3.38 \pm 0.97 \mathrm{mg} / 100 \mathrm{~g}$, vitamin C $52.0 \pm 3.1 \mathrm{mg} / 100 \mathrm{~g}$ ), "Favetta di Terracina" was selected to perform the bioavailability study due to the high values of antioxidant compounds and its characteristic of "product at zero Kilometer".

As reported in Table 2, test meal chemical characterisation (fresh and stored strawberries) includes total antioxidant capacity values and some antioxidant compounds such as vitamin $\mathrm{C}, \alpha$-carotene for carotenoids and polyphenols as well as anthocyanins.

Several studies have shown that the post-harvest factors and storage conditions not only influence the content and composition of phytochemicals in foods, altering the bioavailable amount, but can also modify the chemical structure of the compound [12]. A lot of factors could modify and/or influence the bioavailability of bioactive molecules in humans. The different bioactive components present in strawberries respond differently to conservation treatment, so the storage effect on bioactive molecules present in the strawberries does not seem negligible.

Our results demonstrated the increase of $\alpha$-carotene, quercetin and kaempferol in stored strawberries and lower concentration in anthocyanins and anthocyanidins in fresh ones (Table 2), while no significant differences were obtained for ascorbic acid content.

These results are in accordance with literature data reporting different effects of storage on bioactive compounds in berries and berry products; some compounds and antioxidant activities in berry products are reported to be unchanged or even to increase during processing or storage $[1,28,49]$. The observed increase in quercetin and kampferol during the storage period could be directly associated to degradation of cell structures and so to their higher extractability [19].

Regarding biological samples, no significant differences were found in cholesterol and triglycerides plasma levels after consumption of both fresh and stored strawberries (data not shown).

Table 3 shows vitamin A, vitamin E, vitamin C and carotenoids plasma levels ( $\mu \mathrm{mol} / \mathrm{L}$ ) upon consumption of fresh and stored strawberries. No significant change due to stored strawberries consumption was found in plasma levels

Table 1

Total antioxidant capacity and bioactive compounds in different ecotypes of strawberries (mean \pm s.d.)

\begin{tabular}{|c|c|c|c|c|c|c|}
\hline Product & $\begin{array}{c}\text { FRAP } \\
(\mathrm{mmol} / \mathrm{kg})\end{array}$ & $\begin{array}{c}\text { TRAP } \\
(\mathrm{mmol} / \mathrm{kg})\end{array}$ & $\begin{array}{c}\text { Coumaric acid } \\
(\mathrm{mg} / 100 \mathrm{~g})\end{array}$ & $\begin{array}{l}\text { Quercetin } \\
(\mathrm{mg} / 100 \mathrm{~g})\end{array}$ & $\begin{array}{c}\text { Kaempferol } \\
(\mathrm{mg} / 100 \mathrm{~g})\end{array}$ & $\begin{array}{l}\text { Vitamin C } \\
(\mathrm{mg} / 100 \mathrm{~g}) \\
\end{array}$ \\
\hline Mara des Bois & $17.78 \pm 0.43^{\mathrm{b}}$ & $9.87 \pm 0.28^{\mathrm{b}}$ & $1.24 \pm 0.20^{\mathrm{b}}$ & $3.10 \pm 0.04^{\mathrm{b}}$ & $1.56 \pm 0.59^{b}$ & $49.8 \pm 3.5^{\mathrm{ab}}$ \\
\hline Aprica & $62.85 \pm 3.23^{\mathrm{a}}$ & $16.31 \pm 1.20^{\mathrm{a}}$ & $0.80 \pm 0.31^{\mathrm{b}}$ & $2.46 \pm 0.45^{\mathrm{b}}$ & $3.38 \pm 0.97^{\mathrm{a}}$ & $52.0 \pm 3.1^{\mathrm{ab}}$ \\
\hline Favetta di Terracina & $18.80 \pm 0.70^{\mathrm{b}}$ & $10.02 \pm 0.68^{b}$ & $7.10 \pm 1.70^{\mathrm{a}}$ & $5.0 \pm 0.30^{\mathrm{a}}$ & $1.16 \pm 0.40^{\mathrm{b}}$ & $55.7 \pm 2.5^{\mathrm{a}}$ \\
\hline Commercial & $19.74 \pm 0.68^{b}$ & $10.34 \pm 0.15^{\mathrm{b}}$ & $1.87 \pm 0.84^{b}$ & $2.06 \pm 0.87^{b}$ & $1.14 \pm 0.01^{\mathrm{b}}$ & $44.2 \pm 2.8^{\mathrm{b}}$ \\
\hline
\end{tabular}

Different superscript letters within each column indicate significant differences by Bonferroni's test: a $v s$ b $P<0.05$. 
Table 2

Total antioxidant capacity and bioactive compounds of the experimental meals

\begin{tabular}{lccc}
\hline & Fresh Strawberries & Stored Strawberries & Statistic \\
\hline FRAP $(\mu \mathrm{mol} \mathrm{Fe} / 2 / 300 \mathrm{~g})$ & $6.96 \pm 0.41$ & $6.89 \pm 0.48$ & n.s. \\
TRAP $(\mathrm{mmol} / 300 \mathrm{~g})$ & $2.65 \pm 0.29$ & $2.85 \pm 0.37$ & n.s. \\
$\alpha$-carotene $(\mu \mathrm{g} / 300 \mathrm{~g})$ & $20.58 \pm 5.48$ & $37.53 \pm 7.73$ & $P<0.05$ \\
Vitamin C $(\mathrm{mg} / 300 \mathrm{~g})$ & $119.7 \pm 23.2$ & $127.3 \pm 30.2$ & n.s. \\
Coumaric acid $(\mathrm{mg} / 300 \mathrm{~g})$ & $4.44 \pm 0.93$ & $4.38 \pm 1.52$ & n.s. \\
Quercetin $(\mathrm{mg} / 300 \mathrm{~g})$ & $10.41 \pm 4.57$ & $19.79 \pm 11.46$ & $P<0.05$ \\
Kampferol $(\mathrm{mg} / 300 \mathrm{~g})$ & $5.57 \pm 1.71$ & $9.44 \pm 3.63$ & $P<0.05$ \\
Cyandin 3-glucoside $(\mathrm{mg} / 300 \mathrm{~g})$ & $0.20 \pm 0.22$ & $0.20 \pm 0.05$ & n.s. \\
Pelargonidin 3-glucoside $(\mathrm{mg} / 300 \mathrm{~g})$ & $8.93 \pm 4.20$ & $6.66 \pm 0.97$ & $P<0.05$ \\
Pelargonidin malonil-gluc $(\mathrm{mg} / 300 \mathrm{~g})$ & $0.28 \pm 0.32$ & $0.22 \pm 0.12$ & n.s. \\
Pelargonidin acetil-gluc $(\mathrm{mg} / 300 \mathrm{~g})$ & $0.16 \pm 0.16$ & $0.11 \pm 0.10$ & n.s. \\
\hline
\end{tabular}

n.s. = not significant.

Table 3

Vitamin A, vitamin E, vitamin C and carotenoids plasma levels ( $\mu \mathrm{mol} / \mathrm{L})$ before and after consumption of fresh and stored strawberries. The results are expressed as mean \pm s.e.m. $(n=13)$

\begin{tabular}{|c|c|c|c|c|c|c|c|}
\hline & Baseline & $0.5(\mathrm{~h})$ & $1(\mathrm{~h})$ & $2(\mathrm{~h})$ & $3(\mathrm{~h})$ & $5(h)$ & $8(h)$ \\
\hline \multicolumn{8}{|c|}{ Vitamin A } \\
\hline Fresh & $1.92 \pm 0.13$ & $1.81 \pm 0.11$ & $1.74 \pm 0.08$ & $1.81 \pm 0.11$ & $1.79 \pm 0.12$ & $1.73 \pm 0.12$ & $1.75 \pm 0.11$ \\
\hline Stored & $1.85 \pm 0.11$ & $1.84 \pm 0.12$ & $1.82 \pm 0.13$ & $1.87 \pm 0.12$ & $1.85 \pm 0.11$ & $1.78 \pm 0.12$ & $1.78 \pm 0.12$ \\
\hline \multicolumn{8}{|c|}{ Vitamin E } \\
\hline Fresh & $21.1 \pm 1.26$ & $21.3 \pm 1.26$ & $20.7 \pm 1.26$ & $20.7 \pm 1.26$ & $21.9 \pm 1.48$ & $20.9 \pm 1.26$ & $20.9 \pm 1.26$ \\
\hline Stored & $21.7 \pm 1.26$ & $21.3 \pm 1.26$ & $20.5 \pm 1.48$ & $21.7 \pm 1.26$ & $21.7 \pm 1.48$ & $20.9 \pm 1.26$ & $20.7 \pm 1.26$ \\
\hline \multicolumn{8}{|c|}{ Vitamin $\mathrm{C}$} \\
\hline Fresh & $47.1 \pm 3.4$ & $49.4 \pm 3.4$ & $54.5 \pm 6.2$ & $66.4 \pm 5.1 *$ & $61.3 \pm 5.1^{*}$ & $56.7 \pm 3.4^{*}$ & $52.8 \pm 4.5$ \\
\hline Stored & $42.0 \pm 2.8$ & $52.8 \pm 2.8^{*}$ & $55.8 \pm 5.1 *$ & $65.8 \pm 3.4^{*}$ & $65.3 \pm 4.5^{*}$ & $58.4 \pm 4.0^{*}$ & $51.1 \pm 4.0$ \\
\hline \multicolumn{8}{|c|}{ Lutein plus zeaxanthin } \\
\hline Fresh & $0.21 \pm 0.02$ & $0.19 \pm 0.01$ & $0.19 \pm 0.01$ & $0.20 \pm 0.01$ & $0.21 \pm 0.02$ & $0.20 \pm 0.02$ & $0.19 \pm 0.02$ \\
\hline Stored & $0.21 \pm 0.02$ & $0.19 \pm 0.01$ & $0.21 \pm 0.01$ & $0.19 \pm 0.01$ & $0.20 \pm 0.02$ & $0.19 \pm 0.01$ & $0.18 \pm 0.01$ \\
\hline \multicolumn{8}{|c|}{ Criptoxanthin } \\
\hline Fresh & $0.23 \pm 0.06$ & $0.21 \pm 0.05$ & $0.20 \pm 0.04$ & $0.21 \pm 0.05$ & $0.23 \pm 0.05$ & $0.21 \pm 0.05$ & $0.20 \pm 0.04$ \\
\hline Stored & $0.21 \pm 0.04$ & $0.20 \pm 0.04$ & $0.22 \pm 0.03$ & $0.20 \pm 0.04$ & $0.19 \pm 0.03$ & $0.20 \pm 0.04$ & $0.18 \pm 0.04$ \\
\hline \multicolumn{8}{|c|}{ Lycopene } \\
\hline Fresh & $0.82 \pm 0.07$ & $0.77 \pm 0.05$ & $0.80 \pm 0.06$ & $0.79 \pm 0.06$ & $0.79 \pm 0.07$ & $0.78 \pm 0.06$ & $0.80 \pm 0.06$ \\
\hline Stored & $0.80 \pm 0.07$ & $0.80 \pm 0.07$ & $0.89 \pm 0.10$ & $0.83 \pm 0.06$ & $0.80 \pm 0.06$ & $0.83 \pm 0.06$ & $0.86 \pm 0.07$ \\
\hline \multicolumn{8}{|c|}{$\alpha$-carotene } \\
\hline Fresh & $0.08 \pm 0.01$ & $0.08 \pm 0.01$ & $0.09 \pm 0.02$ & $0.09 \pm 0.02$ & $0.11 \pm 0.02^{\#}$ & $0.11 \pm 0.02^{\#}$ & $0.10 \pm 0.01^{\#}$ \\
\hline Stored & $0.09 \pm 0.01$ & $0.10 \pm 0.02$ & $0.10 \pm 0.02$ & $0.09 \pm 0.02$ & $0.08 \pm 0.02$ & $0.09 \pm 0.01$ & $0.07 \pm 0.01^{*}$ \\
\hline \multicolumn{8}{|c|}{$\beta$-carotene } \\
\hline Fresh & $0.42 \pm 0.09$ & $0.39 \pm 0.09$ & $0.43 \pm 0.12$ & $0.40 \pm 0.11$ & $0.45 \pm 0.13$ & $0.43 \pm 0.11$ & $0.39 \pm 0.10$ \\
\hline Stored & $0.39 \pm 0.08$ & $0.39 \pm 0.10$ & $0.43 \pm 0.10$ & $0.41 \pm 0.09$ & $0.37 \pm 0.08$ & $0.40 \pm 0.08$ & $0.31 \pm 0.07$ \\
\hline
\end{tabular}

$* P<0.05$ vs baseline; ${ }^{\#} P<0.05$ fresh $v s$ stored.

of vitamin A and vitamin E. After the consumption of fresh or stored strawberries there was a significant increase in vitamin $C$ during entire study time respect to baseline, while plasma peaks of maximum absorption at 2 hours were significantly higher after eating stored strawberries respect to fresh ones. 
Table 4

Plasma levels (mean \pm s.e.m.) of thiol groups (SH), uric acid, Ferric Reducing Antioxidant Power (FRAP) and Total Radical-Trapping Antioxidant Parameter (TRAP) before and after ingestion of fresh and stored strawberries

\begin{tabular}{|c|c|c|c|c|c|c|c|c|}
\hline \multirow[t]{2}{*}{ Time (hour) } & \multicolumn{2}{|c|}{ Thiol groups $(\mu \mathrm{mol} / \mathrm{l})$} & \multicolumn{2}{|c|}{ Uric Acid $(\mu \mathrm{M})$} & \multicolumn{2}{|c|}{$\operatorname{FRAP}\left(\mu \mathrm{mol} \mathrm{Fe} e^{+2} / 1\right)$} & \multicolumn{2}{|c|}{ TRAP $(\mathrm{mmol} / \mathrm{l})$} \\
\hline & Fresh & Stored & Fresh & Stored & Fresh & Stored & Fresh & Stored \\
\hline Baseline & $429 \pm 20$ & $428 \pm 22$ & $332 \pm 17$ & $349 \pm 23$ & $911 \pm 152$ & $866 \pm 128$ & $1031 \pm 141$ & $1179 \pm 138^{\#}$ \\
\hline 0.5 & $406 \pm 20$ & $412 \pm 21$ & $332 \pm 29$ & $349 \pm 29$ & $938 \pm 178$ & $926 \pm 133$ & $1060 \pm 203$ & $1178 \pm 148^{\#}$ \\
\hline 1 & $432 \pm 30$ & $424 \pm 21$ & $308 \pm 29$ & $361 \pm 35$ & $927 \pm 179$ & $933 \pm 149$ & $1125 \pm 131$ & $1101 \pm 195$ \\
\hline 2 & $439 \pm 49$ & $425 \pm 23$ & $314 \pm 17$ & $302 \pm 23$ & $948 \pm 182$ & $933 \pm 138$ & $978 \pm 182$ & $1130 \pm 112^{\#}$ \\
\hline 3 & $430 \pm 40$ & $422 \pm 21$ & $326 \pm 29$ & $326 \pm 17$ & $940 \pm 193$ & $929 \pm 136$ & $1022 \pm 192$ & $1110 \pm 196$ \\
\hline 5 & $431 \pm 39$ & $402 \pm 23$ & $380 \pm 23$ & $355 \pm 17$ & $983 \pm 179 *$ & $966 \pm 142 *$ & $1087 \pm 219$ & $1116 \pm 188$ \\
\hline 8 & $409 \pm 20$ & $410 \pm 21$ & $337 \pm 29$ & $343 \pm 29$ & $968 \pm 173^{*}$ & $966 \pm 136^{*}$ & $980 \pm 188$ & $1005 \pm 193^{*}$ \\
\hline
\end{tabular}

$* P<0.05$ vs baseline; ${ }^{*} P<0.05$ fresh $v s$ stored.

Regarding carotenoids plasma levels upon consumption of fresh and stored strawberries, no differences were present.

After consuming fresh strawberries, plasma levels of $\alpha$-carotene significantly increased $(P<0.05)$ at 3,5 and 8 hours time intervals respect to stored ones, while consuming stored strawberries $\alpha$-carotene plasma values significantly decreased after 8 hours compared with baseline. Our published results [4], examining flavonoid and anthocyanins bioavailability after consumption of fresh and stored strawberries have shown that no traces of quercetin and kampferol were revealed in plasma; no anthocyanins plasma levels were present, while coumaric acid, protocatechuic acid and hydroxbenzoic acid were detected. We observed a decrease of Area Under Curve (AUC) in plasma levels of coumaric acid, hydroxybenzoic acid, protocatechuic acid and in the urinary excretion of metabolite after stored strawberries consumption. In addition we proposed a metabolic pathway of pelargonidin-3-glucoside indicating the 4-hydroxybenzoic acid as a major human metabolite.

Table 4 shows the changes of plasma total antioxidant capacity, thiol groups and urate after eating fresh and stored strawberries. We observed high variability among subjects within the experimental period of the study. FRAP values after consumption of fresh and stored strawberries showed a significant increase $(P<0.05)$ at 5 and 8 hours time interval, while a significant decrease in TRAP values was found $(P<0.05)$ at 8 hours respect to baseline after stored strawberries consumption.

No significant differences were observed in both plasma SH groups and uric acid levels.

An increase of FRAP values was obtained according to vitamin C levels over the study time compared with baseline (Table 3). Moreover simple polyphenols produced by the metabolism of bioactive compounds (anthocyanins, flavonoids, proanthocyanidins) could contribute to increase FRAP values [40]. In addition a not significant increase of uric acid levels (contribute to FRAP around 60\%) was present at 5 hours from acute consumption of fresh and stored strawberries.

It was previously shown by many researchers that the FRAP method is unable of assaying either thiol- or carotenoidtype antioxidants [10], probably due to this chemical inertness. As reported by Benzie and Strain [6], the main difference between FRAP and TRAP specifities lies in the FRAP lack of sensitivity for SH groups in antioxidants. On the other hand, the significant decrease of plasma TRAP values at 8 hours could depend on decreasing of single antioxidant including thiol groups, ascorbate and urate plasma levels.

Our results highlight the correlation between plasma endogenous antioxidant and circulating levels of dietary phenolics, underlying the antioxidant action of phenolic metabolites. In addition the results showed that the storage seems to influence the content of bioactive molecules and so their bioavailability.

\section{Acknowledgments}

TRUEFOOD "Traditional United Europe Food" is an Integrated Project financed by the European Commission under the 6th Framework Programme for RTD (Contract n. FOOD-CT-2006-016264). 


\section{References}

[1] K. Aaby, R.E. Wrolstad, D. Ekeberg and G. Skrede, Polyphenol composition and antioxidant activity in strawberry purees; impact of achene level and storage, Journal of Agricultural and Food Chemistry 55 (2007), 5156-5166.

[2] D.K. Asami, Y.J. Hong, D.M. Barrett and A.E. Mitchell, Comparison of the total phenolic and ascorbic acid content of freeze-dried and airdried marionberry, strawberry, and corn grown using conventional, organic, and sustainable agricultural practices, Journal of Agricultural and Food Chemistry 51 (2003), 1237-1241.

[3] J.F. Ayala-Zavala, S.Y. Wang, C.Y. Wang and G.A. Gonzalez-Aguilar, Effect of storage temperatures on antioxidant capacity and aroma compounds in strawberry fruit, Lebensm, -Wiss u-Technol 37 (2004), 687-695.

[4] E. Azzini, P. Vitaglione, F. Intorre, A. Napolitano, A. Durazzo, M.S. Foddai, A. Fumagalli, G. Catasta, L. Rossi, E. Venneria, A. Raguzzini, L. Palomba, V. Fogliano and G. Maiani, Bioavailability of strawberry antioxidants in humans, British Journal of Nutrition 21 (2010), $1-9$.

[5] M. Battino, J. Beekwilder, B. Denoyes-Rothan, M. Laimer, G.J. McDougall and B. Mezzetti, Bioactive compounds in berries relevant to human health, Nutrition Reviews 67 (2009), 1:S145-S150.

[6] I.F.F. Benzie and J.J. Strain, Ferric reducing ability of plasma (FRAP) as a measure of antioxidant power: The FRAP assay, Analytical Biochemistry 239 (1996), 70-76.

[7] A. Bub, B. Watzl, D. Heeb, G. Rechkemmer and K. Briviba, Malvidin-3-glucoside bioavailability in humans after ingestion of red wine, dealcoholized red wine and red grape juice, European Journal of Nutrition 40 (2001), 113-120.

[8] B. Buendía, M.I. Gil, J.A. Tudela, et al., HPLC-MS Analysis of proanthocyanidin oligomers and other phenolics in 15 strawberry cultivars (dagger), Journal of Agricultural and Food Chemistry 58 (2010), 3916-3926.

[9] G. Cao and R.L. Prior, Anthocyanins are detected in human plasma after oral administration of an elderberry extract, Clinical Chemistry 45 (1999), 574-576.

[10] G. Cao and R.L. Prior, Comparison of different analytical methods for assessing total antioxidant capacity of human serum, Clinical Chemistry 44 (1998), 1309-1315.

[11] F. Capocasa, J. Diamanti, B. Mezzetti, S. Tulipani and M. Battino, Breeding strawberry (Fragaria X ananassa Duch) to increase fruit nutritional quality, Biofactors 34 (2008), 67-72.

[12] R. Cermak, A. Durazzo, G. Maiani, V. Böhm, D.R. Kammerer, R. Carle, W. Wiczkowski, M.K. Piskula and R. Galensa, The influence of postharvest processing and storage of foodstuffs on the bioavailability of flavonoids and phenolic acids, Molecular Nutrition \& Food Research 53 (2009), S184-S193.

[13] M.N. Clifford and A. Scalbert, Ellagitannins-nature, occurrence and dietary burden, Journal of the Science of Food and Agriculture 80 (2000),1118-1125.

[14] B.R. Cordenunsi, M.I. Genovese, J.R.O. Nascimento, N.M.A. Hassimotto, R.J. Dos Santos and F.M. Lajolo, Effects of temperature on the chemical composition and antioxidant activity of three strawberry cultivars, Food Chemistry 91 (2005), 113-121.

[15] A. Crozier, T. Yokota, I.B. Jaganath, S.C. Marks, M. Saltmarsh and M.N. Clifford, Secondary metabolites in fruits, vegetables, beverages and other plant based dietary components, in Plant Secondary Metabolites: Occurrence, Structure and Role in the Human Diet, Blackwell Publishing, Oxford, UK, 2006, pp. 208-302.

[16] F. Galvano, L. La Fauci, G. Lazzarino, V. Fogliano, A. Ritieni, S. Ciappellano, N.C. Battistini, B. Tavazzi and G. Galvano, Cyanidins: metabolism and biological properties, Journal of Nutritional Biochemistry 15 (2004), 2-11.

[17] A. Ghiselli, M. Serafini, F. Natella and C. Scaccini, Total antioxidant capacity as a tool to assess redox status: critical view and experimental data, Free Radical Biology \& Medicine 29 (2000),1106-1114.

[18] S. Hakkinen, M. Heinonen, S. Karenlampi, H. Mykkanen, J. Ruuskanen and R. Torronen, Screening of selected flavonoids and phenolic acids in 19 berries, Food Research International 32 (1999), 345-353.

[19] S. Hakkinen, S.O. Karenlampi, H.M. Mykkanen and A.R. Torronen, Influence of domestic processing and storage on flavonol contents in berries, Journal of Agricultural and Food Chemistry 48 (2000), 2960-2965.

[20] S.M. Hannum, Potential impact of strawberries on human health: a review of the science, Critical Reviews in Food Science and Nutrition 44 (2004), 1-17. Review

[21] M. Heinonen, Antioxidant activity and antimicrobial effect of berry phenolics-a Finnish perspective, Molecular Nutrition \& Food Research 51 (2007), 684-691.

[22] M.G.L. Hertog, C.H. Hollman and D.P. Venema, Optimization of a quantitative HPLC determination of potentially anticarcenogenic flavonoids in vegetables and fruits, Journal of Agricultural and Food Chemistry 40 (1992), 1591-1598.

[23] S. Hogan, H. Chung, L. Zhang, J. Li, Y. Lee, Y. Dai and K. Zhou, Antiproliferative and antioxidant properties of anthocyanin-rich extract from açai, Food Chemistry 118 (2010), 208-214.

[24] M.L. Hu, Measurement of protein thiol groups and glutathione in plasma, Methods in Enzymology 233 (1994), 380-385.

[25] A.L. Huntley, The health benefits of berry flavonoids for menopausal women: Cardiovascular disease, cancer and cognition, Maturitas 63 (2009), 297-301.

[26] C.D. Kay, G. Mazza, B.J. Holub and J. Wang, Anthocyanin metabolites in human urine and serum, British Journal of Nutrition 91 (2004), 933-942. 
[27] J.M. Koponen, A.M. Happonen, P.H. Mattila and A.R. Törrönen, Contents of anthocyanins and ellagitannins in selected foods consumed in Finland, Journal of Agricultural and Food Chemistry 55 (2007), 1612-1619.

[28] M. Kosar, E. Kafkas, S. Paydas and K. Can Baser, Phenolic composition of strawberry genotypes at different maturation stages, Journal of Agricultural and Food Chemistry 52 (2004), 1586-1589.

[29] L. Krenn, M. Steitz, C. Schlicht, H. Kurth and F. Gaedcke, Anthocyanin- and proanthocyanidin-rich extracts of berries in food supplementsanalysis with problems, Pharmazie 62 (2007), 803-812.

[30] J.D. Lambert, J. Hong, G. Yang and C.S. Yang, Inhibition of carcinogenesis by polyphenols: evidence from laboratory investigation, American Journal of Clinical Nutrition 81 (2005), 284S-291S.

[31] F.C. Lau, B. Shukitt-Hale and J.A. Joseph, Beneficial effects of berry fruit polyphenols on neuronal and behavioral aging, Journal of the Science of Food and Agriculture 86 (2006), 2251-2255.

[32] C. Luceri, L. Giannini, M. Lodovici, E. Antonucci, R. Abbate, E. Masini and P. Dolara, p-coumaric acid, a common dietary phenols inhibits platelet activity in vitro and in vivo, British Journal of Nutrition 97 (2007), 458-463.

[33] K.R. Määttä-Riihinen, A. Kamal-Eldin, P.H. Mattila, A.M. González-Paramás and A.R. Törrönen, Distribution and contents of phenolic compounds in eighteen Scandinavian berry species, Journal of Agricultural and Food Chemistry 52 (2004), 4477-4486.

[34] G. Maiani, G. Pappalardo, A. Ferro-Luzzi, A. Raguzzini, A. Azzini, A. Guadalaxara, M. Trifero, T. Frommel and S. Mobarhan, Accumulation of $\beta$-carotene in normal colorectal mucosa and colonic neoplastic lesions in humans, Nutrition \& Cancer 24 (1995), 23-31.

[35] S.A. Margolis and R.M. Schapira, Liquid chromatography measurement of L-ascorbic acid and D-ascorbic acid in biological samples, Journal of Chromatography B: Biomedical Sciences and Applications 690 (1997), 25-33.

[36] S.M. Margolis, C.P. Robert and R.G. Ziegler, Ascorbic and dehydroascorbic acids in plasma preserved with dithiothreitol or metaphosphoric acid, Clinical Chemistry 36 (1990), 1750-1755.

[37] G. Mazza, C.D. Kay, T. Cottrell and B.J. Holub, Absorption of anthocyanins from blueberries and serum antioxidant status in human subjects, Journal of Agricultural and Food Chemistry 50 (2002), 850-857.

[38] T.K. McGhie, G.D. Ainge, L.E. Barnett, J.M. Cooney and D.J. Jensen, Anthocyanin glycosides from berry fruit are absorbed and excreted unmetabolized by both humans and rats, Journal of Agricultural and Food Chemistry 51 (2003), 4539-4548.

[39] M.E. Olsson, J. Ekvall, K.E. Gustavsson, J. Nilsson, D. Pillai, I. Sjöholm, U. Svensson, B. Akesson and M.G. Nyman, Antioxidants, low molecular weight carbohydrates, and total antioxidant capacity in strawberries (Fragaria $\times$ ananassa): effects of cultivar, ripening, and storage, Journal of Agricultural and Food Chemistry 52 (2004), 2490-2498.

[40] R. Pulido, L. Bravo and F. Saura-Calixto, Antioxidant activity of dietary polyphenols as determined by a modified ferric reducing/antioxidant power assay, Journal of Agricultural and Food Chemistry 48 (2000), 3396-3402.

[41] A. Raffo, G. La Malfa, V. Fogliano, G. Maiani and G. Quaglia, Seasonal variations of quality attributes and antioxidant content in cherry tomatoes (Lycopersicon Cv Naomi F1), Journal of the Science of Food and Agriculture 50 (2002), 6550-6556.

[42] A. Rossi, I. Serraino, P. Dugo, R. Di Paola, L. Mondello, T. Genovese, D. Morabito, G. Dugo, L. Sautebin, A.P. Caputi and S. Cuzzocrea, Protective effects of anthocyanins from blackberry in a rat model of acute lung inflammation, Free Radical Research 37 (2003), 891-900.

[43] J. Scalzo, A. Politi, N. Pellegrini, B. Mezzetti and M. Battino, Plant genotype affects total antioxidant capacity and phenolic content in fruit, Nutrition 21 (2005), 207-213.

[44] M. Serafini, R. Bugianesi, M. Salucci, E. Azzini, A. Raguzzini and G. Maiani, Effect of acute ingestion of fresh and stored lettuce (Lactuca sativa) on plasma total antioxidant capacity and antioxidant levels in human subjects, British Journal of Nutrition 88 (2002), 615-623.

[45] I. Serraino, L. Dugo, P. Dugo, L. Mondello, E. Mazzon, G. Dugo, A.P. Caputi and S. Cuzzocrea, Protective effects of cyanidin-3-Oglucoside from blackberry extract against peroxynitrite-induced endothelial dysfunction and vascular failure, Life Sciences 73 (2003), 1097-1114.

[46] K.E. Sharpless, M. Arce-Osuna, J. Brown-Thomas and L.M. Gil, Value assignment of retinol, retinyl palmitate, tocopherol and carotenoid concentrations in standard references material 2383 (baby food composite), Journal of AOAC International 82 (1999), $288-296$.

[47] Y. Shin, R.H. Liu, J.F. Nock, D Holliday and C.B. Watkins, Temperature and relative humidity effects on quality, total ascorbic acid, phenolics and flavonoid concentrations, and antioxidant activity of strawberry, Postharvest Biology and Technology 45 (2007), 349-357.

[48] Y. Shin, J.A. Ryu, R.H. Liu, J.F. Nock and C.B. Watkins, Harvest maturity, storage temperature and relative humidity affect fruit quality, antioxidant contents and activity, and inhibition of cell proliferation of strawberry fruit, Postharvest Biology and Technology 49 (2008), 201-209.

[49] S. Tulipani, B. Mezzetti, F. Capocasa, S. Bompadre, J. Beekwilder, C.H. de Vos, E. Capanoglu, A. Bovy and M. Battino, Antioxidants, phenolic compounds, and nutritional quality of different strawberry genotypes, Journal of Agricultural and Food Chemistry 56 (2008), 696-704.

[50] S. Tulipani, S. Romandini, F. Busco, S. Bompadre, B. Mezzetti and M. Battino, Ascorbate, not urate, modulates the plasma antioxidant capacity after strawberry intake, Food Chemistry 117 (2009), 181-188.

[51] P. Vitaglione, G. Donnarumma, A. Napolitano, F. Galvano, A. Gallo, L. Scalfi and V. Fogliano, Protocatechuic acid is the major human metabolite of cyanidin-glucosides, Journal of Nutrition 137 (2007) 2043-2048. 
[52] S.Y. Wang, R. Feng, Y. Lu, L. Bowman and M. Ding, Inhibitory effect on activator protein-I, nuclear factor-kappa B, and cell transformation by extracts of strawberries (Fragaria $\times$ ananassa Duch.), Journal of Agricultural and Food Chemistry 53 (2005), 4187-4193.

[53] X. Wu, G. Cao, R.L. Prior, Absorption and metabolism of anthocyanins in human subjects following consumption of elderberry or blueberry, Journal of Nutrition 132 (2002), 1865-1871.

[54] X. Wu, G.R. Beecher, J.M. Holden, D.B. Haytowitz, S.E. Gebhardt, R.L. Prior, Concentrations of anthocyanins in common foods in the United States and estimation of normal consumption, Journal of Agricultural and Food Chemistry 54 (2006), 4069-4075.

[55] Y. Zhang, N.P. Seeram, R. Lee, L. Feng and D. Heber, Isolation and Identification of Strawberry Phenolics with Antioxidant and Human Cancer Cell Antiproliferative Properties, Journal of Agricultural and Food Chemistry 56 (2008), 670-675.

[56] S.J. Zunino, D.H. Storms, Y. Zhang and N.P. Seeram, Growth arrest and induction of apoptosis in high-risk leukemia cells by strawberry components in vitro, Journal of Functional Foods 1 (2009), 153-160. 